\title{
English Teachers' Understanding of Language Assessment
}

\author{
Dina Novita Wijayanti ${ }^{*}$ \\ ${ }^{1}$ English Education Department, Muria Kudus University, Kudus, Indonesia
}

\begin{tabular}{|l|l|l|l|}
\hline Contact: & Dina Novita Wijayanti & $\boldsymbol{Q}$ & dinaumk1@gmail.com \\
\hline
\end{tabular}

\begin{abstract}
In reality, most of the teachers assessed the students' works only by using test. Ideally, as teachers whose job assessed the students' works, they must understand and apply the concept of measurement include testing, assessment, examination, and evaluation. In fact, we sometimes found phenomena where the teachers got confused to differ among them and nowadays learning process is as important as learning product. Because of the reasons above, the researcher was interested in describing how far the English teachers understand about language assessment and how they assessed and interpreted the students' work. The research was conducted in the form of qualitative and quantitative research. The subjects of the study were 2 English teachers from SMA 1 Kudus and 2 English teachers from SMP 3 Bae Kudus. The instruments used were interview and documentation. The findings showed that only $25 \%$ teachers understood language assessment. The others found difficulties in differentiating and applying measurement concept. Moreover, the teacher's way in assessing and interpreting was insufficient because in assessing the students' capacity, learning process is as important as learning product nowadays.
\end{abstract}

KEYWORDS:

English Teachers;

Understanding;

Language Assessment

\section{Introduction}

Teacher plays an important role in education especially increases the quality of the students. The position of the teacher is one of the aspects which determines the quality of the students itself. A qualified teacher is one who has a positive effect on students' learning and development through a combination of content mastery, a broad set of pedagogic skills and communications or interpersonal skills (Swanson, 2011, p. 5). In other words, the teachers' role in education is very crucial because he or she transfers his or her knowledge through communication and threats the students with different learning styles. The other's job of a teacher related his job in teaching is a 
teacher must have the ability to determine the quantity of achievement of the learners or students by means of appropriate measuring instrument. That process is called measurement.

Measurement is a systematic procedure of determining the quantity or extent of all measureable dimensions include intelligence, interest, aptitude, values, health and other personality traits of pupils and students plus their scholastic achievements in their school subjects (Hartoyo, 2011, p. 2). It means a teacher also has the ability to measure the intelligence, interest, aptitude and values of the students by using appropriate instrument. In this case, there are some forms of measurement include test, questionnaire, rating, scales and checklist (Hartoyo, 2011, p. 2). Related to the measurement, one of the forms of it is test. Ideally, a teacher must understand the meaning of test itself. Moreover, he or she must understand the meaning of the other concepts of educational measurement such as testing, assessment, examination and evaluation. The researcher's motivation in discussing the topic about the English teachers' understanding because nowadays in assessing the students' capacity, learning process is as important as learning product. Moreover, if the English teacher assess the students' work by using some aspects such as by adding the activeness in daily activity along teaching and learning process, it will be fairer than assessing only by using tests (mid semester test and also final test). For example, sometimes we find phenomena where the students got good mark for English test because of cheating while in their daily activities, they are not active in the class. On the other hand, sometimes clever students, they are active in the class and unluckily the score of English tests are less than those who did cheating. The contribution of this study for education is the English teacher will get new information and knowledge and apply the concept of measurement to assess the students' work by focusing not only for the product but also process also important by considering the previous explanation. There are some previous studies about the topic. The first previous research was conducted by (Galih, 2017). The study entitled "The Role of 
Portfolio Assessment and Reflection on Process of Writing". The previous study has devoted itself to investigate the effect of using portfolio assessment technique and reflection activities. The result of the study showed students' response to questionnaire was positive to portfolio based learning. The second previous study was conducted by (Dayal, 2016) entitled Fijian Teachers' Conceptions of Assessment. The study set out to explore Fijian teacher's conceptions of assessment. The results indicate that Fijian pre-service teachers generally held an assessment of learning view, while majority of in-service teachers see assessment as formative. Those previous studies support the recent study.

Discussing about the topic, it means it discusses also about a test. A test is a method of measuring person's ability, knowledge or performance in a given domain to determine a student's ability to compete certain tasks or demonstrate mastery of a skill or knowledge content (Brown, 2004, p. 3). From the definition above, it can be inferred that the test is a method to measure ability of the students in one topic in certain subject. For example related to English subject. The teacher has explained about simple past tense then he or she gives test related to the topic has been taught (simple past tense) to the students. Because the test is given after the teacher explained one topic in certain subject. Commonly, the test is given by the teacher to the students for 4 until 5 times in a semester.

On the other hand, assessment is an ongoing process that encompasses a much wider domain. Whenever a student responds to a question, offers comment or tries out a new word, or structure the teacher subconsciously makes an assessment of the students' performance. It is the process of gathering information to monitor progress and make educational decisions if necessary (Kizlik, 2016, p. 3). In other words, assessment consists of process whenever the student responds to a question, offers a comment or tries out. So, the teacher's role in assessing the students is not only from the test given after the teacher explained one topic but also the teacher also must consider 
with the activity of the students in teaching learning process whether they are active or not in class, how his or her attitude to the teacher etc.

If the teacher only assesses the students from the test, it is not fair because sometimes he or she finds phenomena where certain students have low mastery in passing the test but they are active in class for example he or she usually asks to the teacher when finding difficulties in understanding certain topic, they answer the teacher's questions, they have good behavior etc. All those components must be considered by the teacher in assessing his or her students. From the explanation above, it is clear that assessment is an ongoing process where the teacher must assess his or her students that can be done through certain combination ways. They are formal (test), formal (observation). For formal way, the teacher assesses the students by giving several tests while for the informal way by observing the activity of the students whether they are active or not in joining the teaching learning process and their attitude to the teacher. Best practice in assessment is ongoing assessment through a variety of differentiated tasks and strategies, both formal and informal, so that sufficient evidence (Zimmaro, 2004, p. 9). So, assessment is a broad term that includes testing.

A test is a special form of assessment. It made under contrived circumstances especially so that they may be administered (Hartoyo, 2011, p. 6). In other words, all tests are assessment, but not all assessments are tests. The key to teacher made test or the way to assess the students is to make the tests a part of assessment -not separate from it. Test should be instructional and ongoing (Stiggins, 1994, p. 96). From the explanation above, the key point is the teacher should assess the students through ongoing process (assessment) not only assess from the test but also from their activity in learning process also.

The next is examination. It is test that is school scheduled tend to cover more of the curriculum and count more than other forms of evaluation (Stiggins, 1994, p. 96). It means that they are tests which are conducted 
together with the other subjects and they are school scheduled to know whether the students can pass them or not. On the other hand, evaluation is the systemic gathering information of the students through assessment then it evaluates, judges and compares the quality of the students in order to make decision. One of the characteristics of evaluation is it uses various strategies of assessment such as achievement, aptitude, personality, character, test, questionnaire, interviews, observation technique etc (Hartoyo, 2011, p. 3). So, it is clear that evaluation consists of some assessment in order to judge the quality of students by gathering the information through test, observation, aptitude of the students.

Based on the explanation above, ideally as a teacher whose job assesses the students' works, he or she must understand and apply the concept of measurement that consists of testing, assessment, examination and evaluation. In fact, we sometimes find phenomena where the teacher gets confused to differ among them. They think all of them the same. Assessment is popular but sometimes misunderstood term in current educational practice. Sometimes, we think of testing and assessing as synonymous, but they are certainly not (Hartoyo, 2011, p. 7). One of the misunderstanding of assessment is it is only "test" at the end of a unit of work of series of lessons (Zimmaro, 2004, p. 10). Correct definition of assessment is an ongoing process where the teacher not only assesses the students from test but also from the activity of the students in teaching learning process whether they are active or not in class, how is the attitude to the teacher etc. On the other hand, test is a method to measure ability of the students in one topic in certain subject that is conducted at the end of a unit of work or series of lessons. In other words, test can be useful device but it is only one among many procedures and tasks that the teacher can ultimately use to assess students (Hartoyo, 2011, p. 7).

Considering on the phenomena above, the researcher finds that there is discrepancy (gap) between the expectation (the ideal situation should be) and the fact about teacher's understanding about test, assessment, examination 
and evaluation. The teachers today perhaps more so than ever before, have a need to be knowledgeable consumers of test information constructors of assessment instruments and even teachers about testing (Zimmaro, 2004, p. 4). In other words, the teachers today must know or have a need to be knowledgeable consumers of test information. Moreover, the position of the teacher transfers the knowledge to the students. If the teacher does not understand with language testing, how he or she assesses the students. It will make the teacher cannot maximize in the way to assess the students' works. For example the teacher just assesses the students from the test. Whereas we know that the optimal way to assess the students is by applying assessment concept. Nowadays, learning process is as important as learning product. That is one of the reasons why the researcher is interested in carrying out an indepth interview to the teacher.

The other reason is the researcher wants to interpret how the teacher assesses and interprets the students' work. One of the misunderstanding of assessment is it is only the "test" at the end of a unit of work or series of lessons (Zimmaro, 2004, p. 10). In other words, the teacher usually knows that the way to assess the students' work is by using only test. So, the ideal way to interpret the students' work is by applying assessment concept. It is an ongoing process that encompasses a much wider domain (Brown, 2004, p. 4). Whenever a student responds to a question, offers, comment or tries out a new word, or structure the teacher subconsciously makes an assessment of the students' performance. From the explanation above, it is clear that assessment is an ongoing process where the teacher must assess his or her students that can be done through certain combination ways. They are formal (test), formal (observation).

For formal way, the teacher assesses the students by giving several tests while for the informal way by observing the activity of the students whether they are active or not in joining the teaching learning process and their attitude to the teacher. Best practice in assessment is ongoing assessment through a 
variety of differentiated tasks and strategies, both formal and informal, so that sufficient evidence (Zimmaro, 2004, p. 9) . So, the researcher can infer that in interpreting the students by using assessment concept, the teacher must focus on process oriented than product oriented, because it will be fair for the students. They are not only being assessed from the test but also from their activity in class whether they are active or not in teaching learning process. If the teacher just emphasizes in the product than the process in students' works, sometimes the teacher faces certain student has high score in final test but in daily test, and daily activity, he or she does not master English that is the importance of interpreting based on assessment concept.

In assessing the students' works, ideally the teacher must consider with the type of test based on the method. There are two kinds of test based on the method (Hartoyo, 2011, p. 30). They are traditional paper and pencil language test and performance test. In traditional paper and pencil language tests are typically used for the assessment either of separate components of language knowledge (grammar, vocabulary) or of the perceptive understanding (listening and reading comprehension) while for performance test are most test of speaking and writing. Listening and reading belong to receptive skills while speaking and writing belong to productive skills. For assessing the listening skill, the teacher must apply a scale as indication of their performance. For example 0-15 points related to visual representation, 0-10 points related to the accuracy and 0-5 points related to symbol and abbreviation. Assessing the speaking skill, the teacher must consider with the importance of rating scale that consists of range, accuracy, fluency, interaction, and coherence. Assessing reading, the teacher must consider the following scale. They are whether the students express accurately the main idea and supporting idea, whether it is written by the students' own words or not, cohesion coherence.

There are 5 types of reading tests such as perceptive, selective, interactive and extensive. For reading test in the form of selective (multiple choice) the teacher may use formula to assess the students. It is objective than the other 
tests. One of the advantages of multiple choice items are enable to rapid scoring, which is often done by scoring machine (Burton, 1991, p. 5). So, the way the teacher assesses the students' work is easier in the form of reading test of multiple choice because it is objective. Writing the score will be reduced if the students write the essay not in the ideal form. For example the maximal score is 10 . The students will get score 10 if they write clear competence in writing on both the rhetorical and syntactic levels, while for incomplete writing the score will be reduced. Ideally, it will be better if the teacher assesses the students by using grading scale created by the expert because it is more valid than make by the teacher's own creation.

Based on the explanation above, the researcher is interested in conducting a research entitled teachers' understanding in language assessment. The subjects of the research are 2 English teachers from SMA 1 Kudus and 2 English teachers from SMP 3 Bae Kudus. The objectives of conducting this research are to describe how far the teachers understand about language assessment include testing, assessment, examination, and evaluation and how they assess and interpret the students' work because nowadays in assessing the students' capacity, learning process is as important as learning product. Moreover, if the English teacher assess the students' work by using some aspects such as by adding the activeness in daily activity along teaching and learning process, it will be fairer than assessing only by using tests (mid semester test and also final test). For example, sometimes we find phenomena where the students got good mark for English test because of cheating while in their daily activities, they are not active in the class. On the other hand, sometimes clever students, they are active in the class and unluckily the score of English tests are less than those who did cheating.

\section{Method}

In this study, the researcher applies descriptive qualitative and quantitative approaches. Qualitative research tends to be an effort to generate descriptions 
and situational interpretations of phenomena that the researcher can offer colleagues, students, and others for modifying their own understandings of phenomena (Stake, 2015, p. 57). Additionally it seeks to probe deeply into the research setting to obtain in depth understanding about the way things are, why they are that way, and how the participants in the context perceive them. In this case, the researcher conducted in-depth qualitative research or in-depth understanding about teachers' understanding of language assessment. Moreover, the researcher also used quantitative research to describe the teacher's understanding of language assessment. Quantitative research is defined as the systematical investigation of phenomena by gathering quantifiable data and performing statistical, mathematical or computational technique.

The researcher is interested in describing how far the English teachers understand about language assessment include testing, assessment, examination, and evaluation and how they assess and interpret the students' works. Therefore, the subjects of the research are 2 English teachers from SMA 1 Kudus and 2 English teachers from SMP 3 Bae Kudus. The technique used to take the subjects of the study was by using snowball sampling. It is one of the examples of qualitative sampling. The strategy applied was by deciding how many participants were needed, let initial participants recruited additional participants that fitted the researcher's requirements until the desired number was reached (Gay, L. R., Mills, G.E, \& Airasian, 2011, p. 143). After that, collecting the data is by using interview. In other words, the researcher interviews those teachers about how far the English teachers understand about language assessment include testing, assessment, examination, and evaluation and how they assess and interpret the students' work. They have been interviewed around 30 minutes for every English teacher (the researcher records the interview process).Then, transcribing them based on (Eggins, S \& Slade, 1997, pp. 2-5). 
The data of the research are the sentences in teachers' answers related to the questions given by the researcher while for the data source is transcripts of the results of interview. Next, the technique to analyze the data is by identifying and comparing the answers of the teachers related to the questions given by the researcher with the ideal or correct answer stated by the experts of language assessment.

\section{Result}

\section{English Teachers' Understanding of Language Assessment} In this case, the researcher will describe the results of the study entitled English teachers' understanding of language assessment which consists of some aspects such as testing, assessment, examination and evaluation. Hopefully, the result of the study can give contribution especially for the course of assessment in ELT. The subjects of the study are 2 English teachers from SMA 1 Kudus and 2 English teachers from SMP 3 Bae Kudus. The ways they differ 4 aspects of language assessment are as the following.

First interviewee was Mrs. S. She has described testing is every KD (basic competence). On the contrary, she defined assessment is all KD (basic competences) in one semester. Then, examination is evaluation is for all from first year to third year. For example final examination while the definition of evaluation is to check the students' understanding or comprehension then giving evaluation.

The next is second interviewee. She is Mrs. R. She described testing is a formal assessment or a method to measure someone's ability. Then, the definition of assessment is the conclusion of whole processes while examination is the end of the meeting with the material has been ended. Then she defined evaluation is to evaluate the students' ability and it is usually done in the end of the meeting or every meeting.

The third interviewee is Mrs. B. She described testing is a kind of test given after each material of learning. On the other hand, assessment is as a test given 
after some topics. The next, she defined examination is a test given for all materials in the end of semester or may be at the end of the year while evaluation is a test given to find conclusion of the material.

The last interviewee is Mr. K. He explained testing is a set of exercises consisting of questions or items used to determine the students' knowledge or intelligence. On the other hand, assessment is wider than a test because it consists of performance, all kinds of test, performance, skills, written test, and others. The scoring is involving the process because not only the written test determines to know the students' knowledge but also the process for example the active students often ask some questions in teaching learning process or after the teacher is explaining the topics while examination involves all subjects in or at the end of the semester or at the end of the academic year for example the school examination or national examination. It means that all subjects will be examined or will be tested and the students should pass them. Then, he defines evaluation is meant to find the strength and weaknessess of the students in studying the subjects. By discussing the teachers' understanding of language assessment, it will give contribution especially in giving teachers' feedback whether they can reach the goal of teaching learning process or not. Moreover nowadays, in assessing the students' capacity, learning process is as important as product oriented.

\section{The English Teachers' Ways in Assessing and Interpreting the Students' Works}

There are 4 English teachers who have been the subjects of the study. The next research question is how English teachers assess and interpret the students' works. First interviewee is Mrs. SR. She used certain formula in assessing the students. Actually, Mrs. SR answered that she usually makes reading test in the form of multiple choice, so it will be easy for her to assess the students work because it is objective while for interpreting the students' works, Mrs. SR did not only interpret from the final score but also the daily activity of the students. In other words, she emphasized on the process than product because 
sometimes the teacher found phenomena where the final score of certain student was good because cheating.

The next is Mrs. R. She assessed the students' works depend on the type of test. For example if in the form of multiple choice, she used formula, but luckily her school had a software to calculate it in excel. For writing test, she used rubric, sometimes she downloaded it, sometimes made by herself. Furthermore, for interpreting the students' work, she did not only emphasize on the final score but also from the process. As the evidence she said "It contained or it included process score and then analysis every day score and then processed score itself consists of some items".

The third interviewee is Mrs. B. She has told to the researcher that she made reading test in the form of multiple choice although it had not been recorded. Moreover, she used objective scoring because it used formula. In case of interpreting the students' works, she did not only emphasize on the product but also the process as the evidence she said"Not always the student who gets 90 is the best student or clever student".

The fourth interviewee is Mr. K. When Mr. K answered the researcher's question, he said that he was teaching the twelfth year students so he made the reading test in the form of multiple choice although it was not recorded. So, in assessing it uses certain formula to assess it. Moreover, in assessing the reading test in the form of multiple choice is more effective than the other because it was objective while in interpreting the students' work whether the students got bad mark, he did not only focus on it but also their daily activity in class.

\section{Discussion: English Teachers' Understanding of Language Assessment}

There are 4 English teachers who have been the subjects of the research. This section will describe the English teachers' understanding of language assessment. They are given chances to explain the term testing, assessment, examination, and evaluation. 
From the results of interview of first question about the definition of testing, Mrs. SR explained testing is every KD, Mrs. R described testing is a formal assessment or a method to measure someone's ability, Mrs. B described testing is a kind of test given after each material of learning, Mr. K explained testing is a set of exercises consisting of questions or items used to determine the students' knowledge or intelligence. Actually, a test is a method of measuring person's ability, knowledge or performance in a given domain (Brown, 2004, p. 3). It is also supported by the other expert that test is a method to determine a student's ability to compete certain tasks or demonstrate mastery of a skill or knowledge content (Kizlik, 2011, p. 3). From the definition above, it can be inferred that test is a method to measure ability of the students in one topic in certain subject. For example related to English subject. The teacher has explained about simple past tense then the he or she gave a test related to the topic has been taught (simple past tense) to the students. A test is given after the teacher has explained one topic in certain subject. Commonly, the test is given by the teacher to the students for 4 until 5 times in a semester.

Second question is about the definition of assessment. Mrs.SR defined that assessment is all of $K D$ in one semester. Mrs. R defined assessment is the conclusion of whole processes. Mrs. B defined assessment is as a test given after some topics. Mr. $\mathrm{K}$ defined assessment is wider than a test because it consists of performance, all kinds of test, performance, skills, written test, and others. Actually, the essential point for assessment does not focus on whether it is every KD (basic competence) or all of the KD (basic competence) but to know how the teacher assesses the students whether it is based on only the test or the teacher also considers with the activity of the students being active or not in the class. For example the student responds to a question, offers a comment, the attitude to the teacher etc.

Assessment is an ongoing process that encompasses a much wider domain (Brown, 2004, p. 4). It means whenever a student responds to a question, offers a comment, or tries out a new word or structure, the teacher 
subconsciously makes an assessment of the students' performance. So, assessment means in assessing the students, the teacher must focus on an ongoing process that encompasses a much wider domain. Whenever a student responds to a question, offers comment or tries out a new word, or structure the teacher subconsciously makes an assessment of the students' performance. In other words, the teacher focuses an ongoing process to assess the students. He or she assesses the students not only from the test but also with the activity of the students being active or not in the class or for example the student responds to a question, offers a comment, the attitude to the teacher etc.lt means that nowadays in assessing the students learning process is as important as learning product (Ozenc, 2016, p. 95)

If the teacher just assesses the students from the test, it is not fair because sometimes the teacher finds phenomena where certain students have low mastery in passing the test but they are active in class for example he or she usually asks to the teacher, if he or she finds difficulties in understanding certain topic, they answer the teacher's questions, they have good behavior. All those components must be considered by the teacher in assessing his or her students. The teacher must assess his or her students that can be done through certain combination ways. They are formal (test), informal (observation). For formal (summative test) way, the teacher assesses the students by giving several tests while for the informal way (formative test) by observing the activity of the students whether they are active or not in joining the teaching learning process and their attitude to the teacher.

Best practice in assessment is ongoing assessment through a variety of differentiated tasks and strategies, both formal and informal, so that sufficient evidence (Zimmaro, 2004, p. 9). So, assessment is a broad term that includes testing. A test is a special form of assessment. In other words, all tests are assessment, but not all assessment are tests. The key to teacher made test or the way to assess the students is to make the tests a part of assessment -not separate from it (Stiggins, 1994, p. 96). Test should be instructional and 
ongoing. From the explanation above, the key point is the teacher should assess the students through ongoing process (assessment) not only assess from the test but also from their activity in learning process also.

The next question is examination, Mrs.SR defined the examination as evaluation is for all from first year to third year, for example final examination. Mrs. $R$ defined examination is the end of the meeting with the material has been ended. Mrs. B defined examination is a test given for all materials in the end of semester or may be at the end of the year. Mr. K defined examination involves all subjects in or at the end of the semester or at the end of the academic year for example the school examination or national examination.

Actually, the essential of the examination is whether the test is conducted with the other tests in certain schedule to know whether the students pass it or not in examination. Examinations are tests that are school scheduled tend to cover more of the curriculum and count more than other forms of evaluation (Stiggins, 1994, p. 96). It means that examinations are tests that are conducted together with the other subjects and they are school scheduled to know whether the students can pass them or not in the examination.

The last question is about the definition of evaluation. Mrs.SR defined evaluation was given after the teacher gave material to her students then she evaluated the students' understanding. Mrs. R defined evaluation is to evaluate the students' ability and it is usually done in the end of the meeting or every meeting. Mrs. B defined evaluation is a test given to find conclusion of the material while Mr. K defined evaluation is examination involves all subjects in or at the end of the semester or at the end of the academic year for example the school examination or national examination. It means that all subjects will be examined or will be tested and the students should pass them. Then, he defines evaluation is meant to find the strength and weaknesses of the students in studying the subjects.

Actually, the essential point of evaluation is the teacher gets information about many students' components of the thing being evaluated consists of 
some assessments in order to judge the quality of students whether they reach the goal of learning task or not by gathering the information through test, observation, aptitude of the students (evaluate the program). Evaluation is examining information about many components of the thing being evaluated and comparing or judging its quality, worth or effectiveness in order to make decision (Zimmaro, 2004, p. 4). One of the characteristics of evaluation is it uses various strategies of assessment such as achievement, aptitude, personality, character, test, questionnaire, interviews, observation technique etc (Hartoyo, 2011 , p. 3). Based on the argument from Hartoyo, it is clear that evaluation consists of some assessments in order to judge the quality of students by gathering the information through test, observation , aptitude of the students.

The Comparison of 4 Teachers in Understanding the Meaning of Language Assessment (testing, assessment, examination and evaluation).

Table 1. Teacher understanding the meaning of language

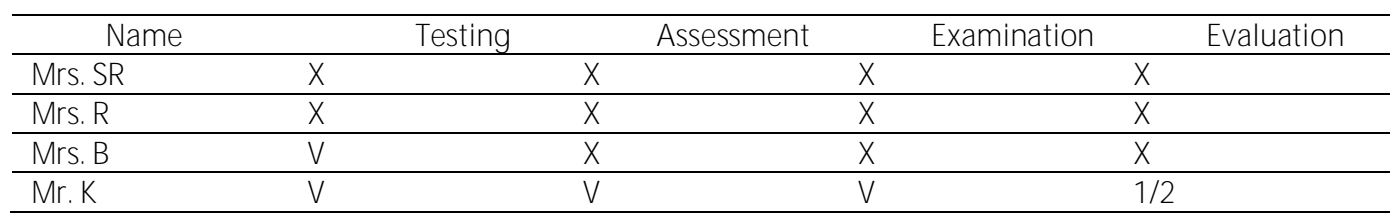

Note : $X$ : Did not understand

\section{$\mathrm{V}:$ Understand}

$1 / 2$ : The answer is not $100 \%$ true but it is a little bit connect with the right answer.

The Score of English Teachers in Understanding Language Assessment

Table 2. Teachers in understanding language assessment

\begin{tabular}{lllll}
\hline Name & Testing & Assessment & Examination & Evaluation \\
\hline Mrs. SR & 0 & 0 & 0 & 50 \\
\hline Mrs. S & 0 & 0 & 0 & 0 \\
\hline Mrs. B & 100 & 0 & 0 & 0 \\
\hline Mr. K & 100 & 100 & 100 & 50 \\
\hline
\end{tabular}

From table 1, the researcher can infer that Mr. K is the best among them in understanding the term testing, assessment, examination and evaluation. The 
other teachers who have been analyzed their understanding of language assessment should make improvement. Ideally, as a teacher whose job asesses the students' works, he or she must understand and apply the concept of measurement that consists of testing, assessment, examination and evaluation.

There are some reasons why the teachers have low mastery in understanding language assessment. First, lack of teachers' knowledge about language assessment. Second, lack of further training on assessment literacy and practice. Usually, the training program that is provided for English teachers mainly focused on the methodological aspect of teaching with lesser attention to the assessment process and of student work or performance. The training program strongly emphasizes on didactic approaches of teaching, enhancing the teachers' knowledge and skills of teaching methodology without strong attention on assessment. Third, in addition, the teachers have been settled and engaged in a long tradition of high stake evaluative system of assessment which drives their current knowledge and understanding of assessment. It is likely that teachers may have an implicit understanding of formative assessment. They are still far legging in the theoretical concept of formative assessment because of the existing tradition or culture of high stake summative testing. Nowadays process oriented is as important as product oriented.

To overcome the problems, the teachers can join seminar, workshop, MGMP, symposium, in house training or can continue to higher level of education because through the events, they can increase their knowledge includes assessment. They can share with the other teachers, lecturers, practitioners of education in order they can get the up to date information of education includes assessment.

\section{The English Teachers' Ways in Assessing and Interpreting the Students' Works}

In this section, it will describe the English teachers' ways in assessing and interpreting the students' works. As has been explained before that there are 4 
English teachers had been the subjects of the study. Then the researcher asked about the ways they assess and interpret the students' works.

When the researcher asked her about the she assessed her students' works, Mrs. SR answered that she used certain formula in assessing the students. Actually, she answered that she usually makes reading test in the form of multiple choice, so it will be easy for her to assess the students' works because it is objective. Then, Mrs. R assessed the students' works depend on the type of test. For example if in the form of multiple choice, she used formula, but luckily her school had a software to calculate it in excel. For writing test, she used rubric, sometimes she downloaded it, sometimes made by herself. Mrs. B has explained to the researcher that she made reading test in the form of multiple choice although it had not been recorded. Moreover, she used objective scoring because it used formula. When Mr. K answered the researcher's question, he said that he was teaching the twelfth year students so he made the reading test in the form of multiple choice although it was not recorded. So, in assessing it used certain formula to assess it. Moreover, in assessing the reading test in the form of multiple choices more effective than the other because it is objective.

Based on the answers above, the researcher can conclude that they understand the concept of assessing the students' works based on the types of the test based on the method. There are two kinds of test based on the method (Hartoyo, 2011, p. 30). They are traditional paper and pencil language test and performance test. In traditional paper and pencil language tests are typically used for the assessment either of separate components of language knowledge (grammar, vocabulary) or of the perceptive understanding (listening and reading comprehension) while for performance test are most test of speaking and writing. Listening and reading belong to receptive skills while speaking and writing belong to productive skills.

For assessing the listening skill, the teacher must apply a scale as indication of their performance. For example $0-15$ points related to visual representation, 
0-10 points related to the accuracy and $0-5$ points related to symbol and abbreviation while for assessing the speaking skill, the teacher must consider with the importance of rating scale that consists of range, accuracy, fluency, interaction, and coherence. On the other hand, for assessing reading, the teacher must consider the following scale. They are whether the students express accurately the main idea and supporting idea, whether it is written by the students' own words or not, cohesion coherence.

There are 5 types of reading test such as perceptive, selective, interactive and extensive. For the reading test in the form of selective (multiple choice) the teacher may use formula to assess the students. It is objective than the other tests. One of the advantages of multiple choice items are enable to rapid scoring, which is often done by scoring machine (Burton, 1991, p. 5). So, based on the argument from the expert it is true that the way the teachers assess the students' works is easier in the form of reading test of multiple choice because it is objective while for writing the score will be reduced if the students do not write the essay in the ideal form. For example the maximal score is 10 . The students will get score 10 if they write clear competence in writing on both the rhetorical and syntactic levels, while for incomplete writing the score will be reduced. Ideally, it will be better if the teacher assesses the students' work by using grading scale created by the expert because it is more valid than make by the teacher's own creation.

In case of interpreting the students' works, Mrs. SR did not only interpret from the final score but also the daily activity of the students. In other words, she emphasized on the process than product because sometimes the teachers found phenomena where the final score of certain student was good because of cheating etc. In line with Mrs. SR, Mrs. R did not only emphasize on the final score but also from the process. As the evidence she said "It contained or it included process score and then analysis every day score and then processed score itself consists of some items". In case of interpreting the students' works, Mrs. B did not only emphasize on the product but also the process as the 
evidence she said "Not always the student who gets 90 is the best student or clever student while in interpreting the students' work whether the students got bad mark, Mr. K did not only focus on students' scores but also their daily activity in class.

The ideal way in interpreting the students' work in by applying assessment concept. Assessment is an ongoing process that encompassess a much wider domain. Whenever a student responds to a question, offers comment or tries out anew word, or structure the teacher subconciously makes an assessment of the students' performance (Brown, 2004, p. 4). The definition of assessment is the process of gathering information to monitor progress and make educational decisions if necessary. In other words, it consists of process whenever the student responds to a question, offers a comment or tries out. So, the teacher's role in assessing the students is not only from the test given after the teacher explained one topic but also the teacher also must consider with the activity of the students in teaching learning process whether they are active or not in class, how his or her attitude to the teacher.

If the teacher just assesses the students from the test, it is not fair because sometimes the teacher finds phenomena where certain students have low mastery in passing the test but they are active in class for example they usually ask to the teacher, if they find difficulties in undertanding certain topic, they answer the teacher's questions etc, they have good behaviour etc. All those components must be considered by the teacher in assessing his or her students because sometimes the teacher finds the score of certain student is too high in fact in daily activity they are not good in English. So, it is possibility for the students to cheat when they are doing their final test. High scores can result from a test that is too easy, from only measuring simple instructional objectives, from biased scoring procedures, or from other factors that influenced the scores, such as cheating or providing unintentional clues to the right answers that is what the teacher must be considerated to interpret the students' wok (Zimmerman, 2018, p. 17) . So, it is better for the teacher to 
apply the assessment concept. That is the best way in interpreting the students' work done by the teacher.

Assign final grades based on more than 1 or 2 exams include their performance on projects, lab assignments, research papers or proposals, and other written work, products, or ideas (Zimmerman, 2018, p. 17). So based on Zimmerman et al, the researcher can infer that the best way in interpreting the students' work done by the teacher is by assigning final grades based on more than 1 or 2 exams include their performance on projects, lab assignments, research papers or proposals, and other written work, products, or ideas. In other words, the teacher must implement the concept of assessment in interpreting the students' work.

Based on the answers of the teachers about the way in assessing and interpreting the students' work, they answer the correct answers when the researcher compares with the answer from the expert of language assessment. This phenomenon happens since an adequate practical understanding of teachers in assessing the students' works because they get this concept when they still studied in universities. When they were still studying in universities, their lecture focused on testing and statistical calculation. Therefore, all the teachers who have been the subjects of the study understand the concept in assessing the students' works. Moreover, they also strengthen their ability in doing it by joining MGMP for English teachers in their region which is held every month.

\section{Conclusion}

The result of the study showed that only 1 from 4 teachers who understand language assessment. It means $25 \%$ teachers can differ among the term testing, assessment, examination, and evaluation while $75 \%$ cannot. There are some reasons why the teachers have low mastery in understanding language assessment. One of them is the teachers are still far legging in the theoretical concept of formative assessment because of the existing tradition or culture of 
high stake summative testing. Moreover, nowadays learning process is as important as leaning product. So, it is better for the English teacher to assess the students by using measurement concept. Related to how they assess and interpret the students' work, all of them understand the concept. As the fact, the researcher compared with the ideal way in assessing and interpreting the students' works from the expert. So overall, the teachers' understanding of language assessment should make improvement. To overcome the problems, the teachers can join seminar, workshop, MGMP, symposium, in house training or can continue to higher level of education because through the events, they can increase their knowledge includes assessment. They can share with the other teachers, lecturers, practitioners of education in order they can get the up to date information of education includes assessment.

\section{References}

Brown. (2004). Language Assessment :Principles and Classroom Practices. white plains: Pearson Education, Inc.

Burton. (1991). Language Assessment.

Dayal, H. C. (2016). Fijian Teachers' Conception of Assessment. Australian J ournal of Teacher Education, 40(8), 43-55.

Eggins, S \& Slade, D. (1997). Analyzing Casual Conversation. London: Creative Print and Design Wales.

Galih, A. S. and. (2017). The Role of Portfolio Assessment and Reflection on Process Writing. Asian EFL J ournal, 7(1), 193-225.

Gay, L. R., Mills, G.E.. \& Airasian, P. . (2011). Educational Research Competencies for Analysis and Applications Tenth Editions. Boston: Pearson Prentice Hall.

Hartoyo. (2011). Language Assessment. semarang: pelita insani.

Kizlik, B. (2011). Measurement, Assessment and Evaluation in Education.

Ozenc, E. G. (2016). the Effect of Process Oriented Writing on the Achievement and Attitude of the Preservice Primary School Teachers: An Example of Mixed Method Study. Education and Practice, 7(15), 227-237.

Stake. (2015). qualitative research. London: Pearson Education , Inc.

Stiggins. (1994). Teacher Made Test.

Swanson. (2011). Improving Student Learning by Supporting Quality Teaching: Key Issues, Effective Strategies. Arlington: Editorial Projects in Education, Inc. Zimmaro. (2004). Writing Good Multiple-Choice Exams.

zimmerman. (2018). Teachers' Understanding of Formative Assessment. Lingua Cultura, 12(1), 17. 